\title{
Aa. Vv., «Ponts / Ponti. Langues littératures civilisations des Pays francophones»
}

\section{Maria Chiara Gnocchi}

\section{(2) OpenEdition}

1 Journals

Édition électronique

URL : https://journals.openedition.org/studifrancesi/46342

DOI : $10.4000 /$ studifrancesi.46342

ISSN : 2421-5856

Éditeur

Rosenberg \& Sellier

\section{Édition imprimée}

Date de publication : 1 octobre 2007

Pagination : 480-481

ISSN : 0039-2944

\section{Référence électronique}

Maria Chiara Gnocchi, «Aa. Vv., «Ponts / Ponti. Langues littératures civilisations des Pays

francophones» », Studi Francesi [En ligne], 152 (LI | II) | 2007, mis en ligne le 30 novembre 2015, consulté le 24 novembre 2021. URL : http://journals.openedition.org/studifrancesi/46342 ; DOI : https://doi.org/10.4000/studifrancesi.46342

Ce document a été généré automatiquement le 24 novembre 2021.

\section{(c) (†) $\odot$}

Studi Francesi è distribuita con Licenza Creative Commons Attribuzione - Non commerciale - Non opere derivate 4.0 Internazionale. 


\title{
Aa. Vv., «Ponts / Ponti. Langues littératures civilisations des Pays francophones»
}

\author{
Maria Chiara Gnocchi
}

\section{RÉFÉRENCE}

«Ponts / Ponti. Langues littératures civilisations des Pays francophones», Enfances, n. 5, 2005, pp. 321.

1 La revue «Ponts / Ponti» consacre sa cinquième livraison aux récits d'enfances (plurielles) francophones. Au fil des contributions, l'enfance se profile comme un état certainement privilégié, de grâce presque, mais «non pas tant comme éden rêvé et perdu, mais plutôt comme moment de lucidité extrême»: loin de pencher du côté de la naïveté, le regard des plus jeunes est souvent très dur, quoique (puisque?) toujours intègre, surtout lorsqu'il est porté sur l'absurdité du monde des adultes et de la condition humaine en général. Il en est ainsi, par exemple, dans différents romans québécois de la Révolution tranquille, que Monique Boucher étudie à l'aide des théories proposées par Gilbert Durand dans Les structures anthropologiques de l'imaginaire: l'archétype de l'enfant s'y accompagne «d'une thématique centrée sur un idéal de perfection, idéal corrompu par l'univers des adultes, et sur l'intégrité à retrouver pour combattre les forces du mal» (p. 56). Ou encore dans l'essai de Sonia Musella sur La petite fille qui aimait trop les allumettes de Gaétan Soucy: l'écrivain québécois «se plait à mettre en scène un univers sombre et atroce où les jeunes gens sont souvent la proie d'un monde adulte corrompu par toutes sortes de perversions touchant aussi bien à la dimension sexuelle qu'à la sphere morale» (p. 88). On remarquera cependant que ce roman constitue un tournant dans la poétique de l'auteur, dans la mesure où, pour la première fois, «un personnage enfant ou adolescent ne se laisse pas annihiler par les revers d'un sort aberrant mais riposte à coups de fantaisie et d'amour démesuré pour la vie» (ibid.). Madeleine Borgomano aborde, quant à elle, quelques romans récents 
produits en Afrique occidentale (Cameroun, Côte d'Ivoire, Mali, Guinée, Sénégal): dans ces récits aussi, l'enfance se définit comme un "'hors lieu" instable où les ambiguïtés et les contradictions de la société se manifestent avec intensité» et fournit, dès lors, un thème privilégié à l'écriture (p. 27). Borgomano, qui choisit de se concentrer sur des récits ayant des petites filles comme héroïnes ou narratrices, remarque que le mot «enfance» ne figure pas dans l'Inventaire des particularités lexicales du Français en Afrique noire: cette notion abstraite n'est pas pertinente dans l'univers africain, où l'enfance est définie comme le temps de la soumission, indépendamment de l'âge de l'individu concerné; dans cette perspective, être une petite fille, c'est être doublement enfant. Le narrateur de La Disparition de la langue française d'Assia Djebar, roman auquel s'attache Giuliva Milò, est par contre un adulte qui, après une vingtaine d'années passées en banlieue parisienne, décide de retourner vivre en Algérie afin de retrouver ses racines. C'est en particulier dans la Casbah d'Alger que le héros et narrateur reprend contact avec son propre passé et avec celui de son peuple: la Casbah, «Nation, Mère et Femme» représente à la fois l'univers enfantin et le cœur de l'Algérie dont l'Histoire s'enracine dans les légendes mythiques. Le dernier article du dossier se différencie nettement des précédents, plus spécifiquement littéraires: Claude Bisquerra présente en effet les résultats d'une vaste enquête sur «L'écolier malgache et la langue française entre 1928 et 1930». La première partie du volume se termine par des inédits, évidemment «enfantins», signés par Parfait Jans, Tierno Monénembo et Herménégilde Chiasson. La deuxième présente une riche série de comptes rendus, une constante de la revue «Ponts / Ponti», dont on ne peut, à chaque fois, que se féliciter. 